Central Washington University

ScholarWorks@CWU

All Faculty Scholarship for the College of the Sciences

$11-5-2015$

\title{
Assessing density functionals for the prediction of thermochemistry of Ti-O-Cl species
}

Yingbin Ge

Douglas DePrekel

Kui-Ting Lam

Kevin Ngo

Phu Vo

Follow this and additional works at: https://digitalcommons.cwu.edu/cotsfac

Part of the Chemistry Commons 


\section{Assessing Density Functionals for the Prediction of Thermochemistry of Ti-O-CI Species}

$$
\text { Yingbin Ge*, Douglas DePrekel, Kui-Ting Lam, Kevin Ngo, and Phu Vo }
$$

Department of Chemistry, Central Washington University, Ellensburg, Washington 98926,

$$
\text { United States }
$$

* Corresponding author. E-mail address: yingbin@cwu.edu. Telephone: 509-963-2817. Fax: 509963-1050 
Abstract: Titanium dioxide $\left(\mathrm{TiO}_{2}\right)$ nanoparticles are widely used in contaminant remediation, photocatalysis, and solar cell manufacturing. The low-cost production of $\mathrm{TiO}_{2}$ nanoparticles via the combustion of titanium tetrachloride $\left(\mathrm{TiCl}_{4}\right)$ in oxygen is thus an important industrial process. To accurately model the flame synthesis of $\mathrm{TiO}_{2}$ nanoparticles, reliable thermodynamic data of Ti-O-Cl species are indispensable but often unavailable. We therefore carried out benchmark calculations, using the left-eigenstate completely renormalized singles, doubles, and perturbative triples (CR-CC $(2,3)$, aka CR-CCL) method with the cc-pVTZ basis set, to obtain the equilibrium structures and vibrational frequencies of selected Ti-O-Cl species; we then performed single-point $\operatorname{CCSD}(\mathrm{T}) /$ aug-cc-pVLZ $(L=3-5)$ calculations to extrapolate the $\operatorname{CCSD}(\mathrm{T}) / \mathrm{CBS}$ energies. After analyzing the experimental and calculated enthalpy of selected Ti-O-Cl species, the standard enthalpy of formation of the $\mathrm{TiOCl}_{2}$ molecule is determined to be $600.5 \mathrm{~kJ} / \mathrm{mol}$ at $298 \mathrm{~K}$. The standard enthalpy of all other Ti-O-Cl species are determined accordingly. Finally, we assessed the accuracy of 42 popular density functionals for the Ti-O-Cl species. Among these assessed functionals, the B98 functional, tightly followed by B97-1 and B3LYP, exhibits the best overall performance in the prediction of the thermochemistry of the TiO-Cl species.

Keywords: titanium oxide; titanium dioxide; thermochemistry; density functional theory; coupled-cluster; CR-CC(2,3); complete basis set; B98; B97-1; B3LYP 


\section{Introduction}

Titanium dioxide $\left(\mathrm{TiO}_{2}\right)$ nanoparticles have been extensively studied because of their applications in contaminant remediation, ${ }^{1}$ photo-catalysis, ${ }^{2-4}$ and dye-sensitized solar cell manufacturing. ${ }^{5,6}$ The recently found self-structural modification ability of the $\mathrm{TiO}_{2}$ nanoparticles make them appealing for other applications. ${ }^{7}$ The low-cost production of $\mathrm{TiO}_{2}$ nanoparticles via the combustion of titanium tetrachloride $\left(\mathrm{TiCl}_{4}\right)$ in an oxygen flame is thus a very important industrial process. Despite the importance of this process, fundamental experimental studies of the thermodynamic properties of $\mathrm{Ti}_{x} \mathrm{O}_{y} \mathrm{Cl}_{z}$ species are scarce, and these experiments often disagree with each other significantly. ${ }^{8-11}$ For example, $\Delta H_{f, 298 K}^{o}$ of $\mathrm{TiCl}_{2}$ and $\mathrm{TiCl}_{3}$ are $-237 \mathrm{~kJ} / \mathrm{mol}$ and $-539 \mathrm{~kJ} / \mathrm{mol}$ in the NIST compilation, ${ }^{8}$ which differ by over $30 \mathrm{~kJ} / \mathrm{mol}$ from Hildenbrand's experimental values of $-205 \mathrm{~kJ} / \mathrm{mol}$ and $-508 \mathrm{~kJ} / \mathrm{mol}$. ${ }^{9}$ Moreover, theoretical calculations sometimes disagree significantly with experiments. In 1963, it was estimated based on experimental data that $\Delta H_{f, 298 K}^{o}\left(\mathrm{TiOCl}_{2}\right)$ is $-546 \mathrm{~kJ} / \mathrm{mol} .{ }^{11}$ This value is formally recorded in the NIST-JANAF table ${ }^{8}$ and had not been challenged until $\sim 40$ years later when Kraft et al. suggested updating $\Delta H_{f, 298 K}^{o}\left(\mathrm{TiOCl}_{2}\right)$ to $-598 \pm 20 \mathrm{~kJ} / \mathrm{mol}$ based on their CCSD(T)//B3LYP/6$311+\mathrm{G}(\mathrm{d}, \mathrm{p})$ calculations in $2007 .{ }^{12}$ Dixon et al. later calculated $\Delta H_{f, 298 K}^{o}\left(\mathrm{TiOCl}_{2}\right)$ to be -593.3 $\mathrm{kJ} / \mathrm{mol}$ based on their coupled-cluster calculations extrapolated to a complete basis set (CBS). ${ }^{13}$ Both Kraft et al.'s ${ }^{12}$ and Dixon et al.'s ${ }^{13}$ results are $\sim 50 \mathrm{~kJ} / \mathrm{mol}$ more negative than the NIST data. ${ }^{8}$ Between the two theoretical studies, Dixon et al.'s calculations are likely more accurate because they not only employed larger basis sets but also included core-valence correlation, scalar relativistic effect, and spin-orbit coupling corrections. While Dixon et al. were mostly interested in the $\mathrm{Ti}_{x}(\mathrm{OH})_{y} \mathrm{Cl}_{z}$ species, ${ }^{13}$ we are focused on the $\mathrm{Ti}_{x} \mathrm{O}_{y} \mathrm{Cl}_{z}$ species involved in the combustion of $\mathrm{TiCl}_{4}$ in pure oxygen. We thus aim to obtain accurate thermochemical data of 
small $\mathrm{Ti}_{x} \mathrm{O}_{y} \mathrm{Cl}_{z}$ species via couple-cluster calculations; these data also serve as benchmark for assessing various density functionals for the calculations of much larger $\mathrm{Tix}_{x} \mathrm{O}_{y} \mathrm{Cl}_{z}$ species. This assessment will enable us to choose the most accurate density functional(s) for the realistic Kinetic Monte Carlo (KMC) ${ }^{14}$ modeling of the flame synthesis of $\mathrm{TiO}_{2}$ nanoparticles in a future work; the physical insight gained from the KMC modeling will not only unveil the fundamental mechanism of the $\mathrm{TiO}_{2}$ flame synthesis but also offer theoretical guidance on how to manipulate the synthetic conditions to obtain $\mathrm{TiO}_{2}$ nanoparticles with desired properties.

Several theoretical studies have resorted to DFT methods for the calculations of the medium to large-sized $\mathrm{Ti}_{x} \mathrm{O}_{y} \mathrm{Cl}_{z}$ species. West et al. carried out B97-1 density functional theory (DFT) calculations to obtain thermochemical and kinetic data of the gas-phase reactions between $\mathrm{Ti}_{x} \mathrm{O}_{y} \mathrm{Cl}_{z}$ species at high temperatures. ${ }^{12,15}$ They compared the B97-1 calculations with the B3LYP, BPW91, PW91, mPWPW91 DFT calculations as well as the MP2, CCSD, and $\operatorname{CCSD}(\mathrm{T}) a b$ initio calculations. B97-1 was found to provide reasonably close energy surfaces to the $\operatorname{CCSD}(\mathrm{T})$ ones for selected small $\mathrm{Ti}_{x} \mathrm{O}_{y} \mathrm{Cl}_{z}$ species. Wilson et al. assessed various DFT methods regarding their accuracy for the third-row transition metal elements and suggest B98 is the most accurate methods for the selected Ti species; ${ }^{16-18}$ a composite approach was used in their work to estimate the benchmark $\operatorname{CCSD}(\mathrm{T}) / \mathrm{CBS}$ energy within a small average $\sim 3 \mathrm{kcal} / \mathrm{mol}$ ( $13 \mathrm{~kJ} / \mathrm{mol}$ ) error. Other than B97-1 and B98, B3LYP was also used to study the molecular structures, energetics, vibrational spectra and other physical properties of $\mathrm{TiCl}_{m}(\mathrm{OH}) n,{ }^{13}$ $\left(\mathrm{TiO}_{2}\right) n,{ }^{19} \mathrm{Ti}_{n} \mathrm{O}_{m}(n=2-4 ; m=1-2 n),{ }^{20}$ and $\mathrm{TiCl}_{m}\left(\mathrm{NH}_{2}\right)_{n}$ species. ${ }^{21}$ While B3LYP has been more commonly used than B98 and B97-1 for the calculations of $\mathrm{Ti}_{x} \mathrm{O}_{y} \mathrm{Cl}_{z}$ and other Ti-containing species, it is likely due to the inertia of chemists sticking to this most popular density functional ${ }^{22}$ without solid evidence suggesting its advantage over B98 and B97-1 for the Ti-O-Cl system. 
Moreover, there exist hundreds of other DFT methods that may or may not be more suitable than B97-1, B98, and B3LYP for modeling the $\mathrm{Tix}_{x} \mathrm{O}_{y} \mathrm{Cl}_{z}$ species. A more comprehensive comparative study is thus desirable to find a DFT method that balances the accuracy of molecular structures, energy, and thermodynamic properties of $\mathrm{Ti}_{x} \mathrm{O}_{y} \mathrm{Cl}_{z}$ species. Herein we assess 42 DFT methods for selected $\mathrm{Ti}_{x} \mathrm{O}_{y} \mathrm{Cl}_{z}$ species. These 42 methods can be categorized as pure DFT methods, hybrid methods with Hartree-Fock (HF) exchange, and double-hybrid methods with HF exchange and MP2-type correlation. They can also be categorized into local spin density approximation (LSDA), generalized-gradient approximation (GGA) which uses the gradients of the electron density, and meta-GGA which includes the second derivative of the electron density or alternatively the kinetic-energy density. Some of the assessed DFT methods include empirical long-range correction to account for dispersion.

In the following sections of this paper, we will introduce the methodology of the coupledcluster benchmark calculation and provide a brief description of the 42 assessed DFT methods. We will then present the coupled-cluster benchmark results and assess the 42 DFT methods before concluding remarks.

\section{Computational Methods}

\subsection{Benchmark coupled-cluster calculations}

The geometries of all studied $\mathrm{Ti}_{x} \mathrm{O}_{y} \mathrm{Cl}_{z}$ species were optimized at the $\mathrm{CR}-\mathrm{CC}(2,3) / \mathrm{cc}-\mathrm{pVTZ}$ level of theory, where $\mathrm{CR}-\mathrm{CC}(2,3)$ stands for the left-eigenstate completely renormalized singles, doubles, and perturbative triples method, ${ }^{23-26}$ and cc-pVTZ stands for the correlation consistent polarized valence triple- $\zeta$ basis set. Although CR-CC $(2,3)$ calculations require more computing power and memory than $\operatorname{CCSD}(\mathrm{T})$, it was chosen for geometry optimization as we find it slightly 
more accurate than the standard $\operatorname{CCSD}(\mathrm{T})$ in the prediction of the geometric parameters and potential energy surfaces especially for bi-radical systems. ${ }^{23-28}$ Among the 4 formulations $(A-D)$ of the CR-CC $(2,3)$ method, ${ }^{23-26}$ formulation $A$ is used to determine the energy gradients. The matrix of energy second derivatives was calculated numerically also using the CR-CC(2,3)/ccpVTZ method, formulation $A$. The vibrational frequencies and zero-point vibrational energies (ZPVE) were calculated with the harmonic-oscillator-rigid-rotor approximation.

Because the CR-CC(2,3)/aug-cc-pV5Z calculations of several $\mathrm{Ti}_{x} \mathrm{O}_{y} \mathrm{Cl}_{z}$ species demand a prohibitively large amount of memory, the standard CCSD(T)/aug-cc-pVLZ $(L=3-5)$ single point energies were used to extrapolate the complete basis set (CBS) energy. Hartree-Fock (HF) limit was obtained using a two-point extrapolation $E_{a u g-c c-p V L Z}^{H F}=E_{a u g-c c-p V \infty Z}^{H F}+$ $A(L+1) e^{-9 \sqrt{L}}$ with $L=4,5 \cdot{ }^{29}$ The correlation was obtained using a three-point extrapolation $E_{\text {aug-cc-pVLZ }}^{\text {correlation }}=E_{\text {aug }-c c-p V \infty Z}^{\text {correlation }}+B \cdot L^{-3}$ with $L=3,4,5 .{ }^{30}$ Although the core-valence correlation, scalar relativistic effect, and spin-orbit coupling are not included in our calculations, the error due to the omissions of these corrections is found small after comparison with $\operatorname{CCSD}(\mathrm{T}) / \mathrm{CBS}$ calculations that include these corrections. ${ }^{13}$

The CR-CC $(2,3)$ geometry optimization and vibrational frequency calculations were carried out using the GAMESS program. ${ }^{31,32}$ The $\operatorname{CCSD}(\mathrm{T}) /$ aug-cc-pVLZ $(L=3-5)$ single-point energy calculations were carried out using the Gaussian 09 software. ${ }^{33}$

\subsection{DFT calculations}

Table 1 groups all assessed DFT methods into the LSDA, GGA, and meta-GGA categories regarding their locality. Besides the B97-D and $\omega \mathrm{B} 97 \mathrm{X}-\mathrm{D}$ methods that include dispersion correction specifically designed for B97 and $\omega \mathrm{B} 97 \mathrm{X}$, we also selected several widely used DFT 
methods including B3LYP, B3PW91, B97, B2PLYP, and M06 to evaluate the empirical dispersion formulas by Grimme with zero-damping D3 parameters ${ }^{34}$ and/or with D3BJ parameters with Becke-Johnson damping. ${ }^{35}$ Table 2 groups all assessed density functionals into the pure, hybrid (with HF exchange), and double-hybrid (with both HF exchange and MP2-type correlation) categories.

Table 1. Categorization of the assessed DFT methods regarding their locality.

\begin{tabular}{|c|c|}
\hline & Density Functionals \\
\hline LSDA & SVWN $^{36-39}$ \\
\hline GGA & 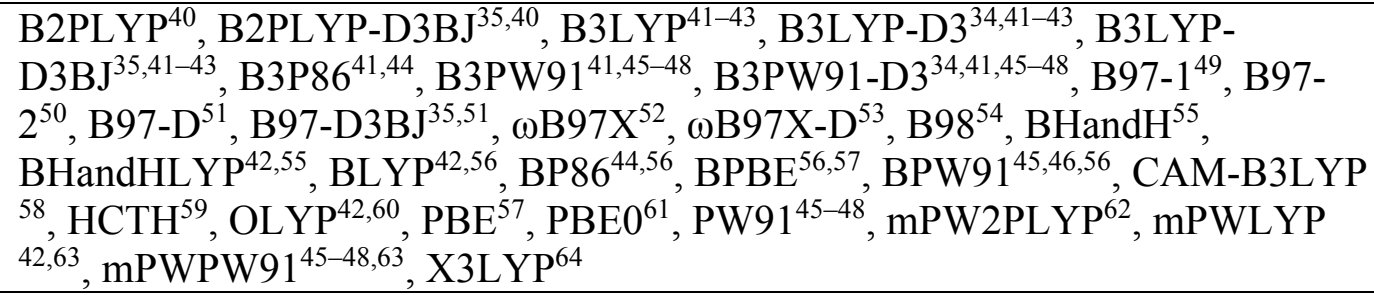 \\
\hline meta-GGA & 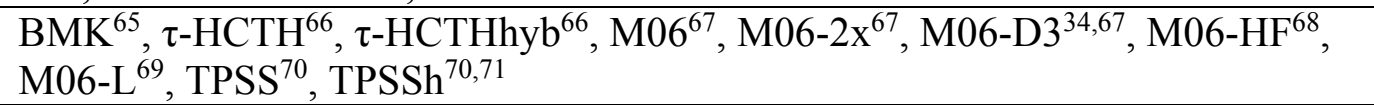 \\
\hline
\end{tabular}

Table 2. Categorization of the assessed DFT methods regarding the inclusion of HF exchange and MP2-type correlation.

\begin{tabular}{ll}
\hline & Density Functionals \\
\hline Pure DFT & B97-D, B97-D3BJ, BLYP, BP86, BPBE, BPW91, HCTH, $\tau$-HCTH, M06-L, \\
& OLYP, PBE, PW91, mPWLYP, mPWPW91, SVWN, TPSS \\
\hline Hybrid & B3LYP, B3LYP-D3, B3LYP-D3BJ, B3P86, B3PW91, B3PW91-D3, B97-1, \\
& B97-2, B97X, $\omega$ B97X-D, B98, BHandH, BHandHLYP, BMK, CAM-B3LYP, \\
& $\tau$-HCTHhyb, M06, M06-2X, M06-D3, M06-HF, PBE0, TPSSh, X3LYP \\
\hline Double & B2PLYP, B2PLYP-D3BJ, mPW2PLYP \\
Hybrid & \\
\hline
\end{tabular}

The DFT calculations of geometry optimization and vibrational frequencies were carried out using the Gaussian 09 software. ${ }^{33}$ In these DFT calculations, the $6-311 \mathrm{G}$ basis set was employed on $\mathrm{O},{ }^{72}$ the McLean-Chandler "negative ion basis set" on $\mathrm{Cl},{ }^{73}$ and the Wachters-Hay all electron basis set on $\mathrm{Ti}^{74,75}$ These basis sets for $\mathrm{O}, \mathrm{Cl}$, and Ti augmented by polarization and 
diffuse functions are denoted 6-311+G(d) in Gaussian ${ }^{33}$ and also referred to as $6-311+\mathrm{G}(\mathrm{d})$ in this paper.

\section{Results and Discussion}

\subsection{Benchmark coupled-cluster calculations}

The CR-CC(2,3) geometric parameters (Figure 1) are compared with available experimental data. ${ }^{8}$ The experimental bond distance of $\mathrm{Cl}_{2}, \mathrm{O}_{2}$, and $\mathrm{TiCl}_{4}$ are $1.988,1.208$, and $2.185 \AA{ }^{8}$ the CR-CC(2,3) bond lengths are slightly longer than the experimental values by $0.018,0.002$, and $0.002 \AA$, respectively. The experimental Ti-O bond lengths in ${ }^{3} \mathrm{TiO}$ and $\mathrm{TiOCl}_{2}$ were estimated to be $1.62 \AA,{ }^{8}$ while the corresponding CR-CC(2,3) bond lengths are 1.635 and $1.620 \AA$. In all cases, the CR-CC $(2,3)$ bond lengths are found to be fairly accurate within a $0.02 \AA$ deviation from the available experimental data. 

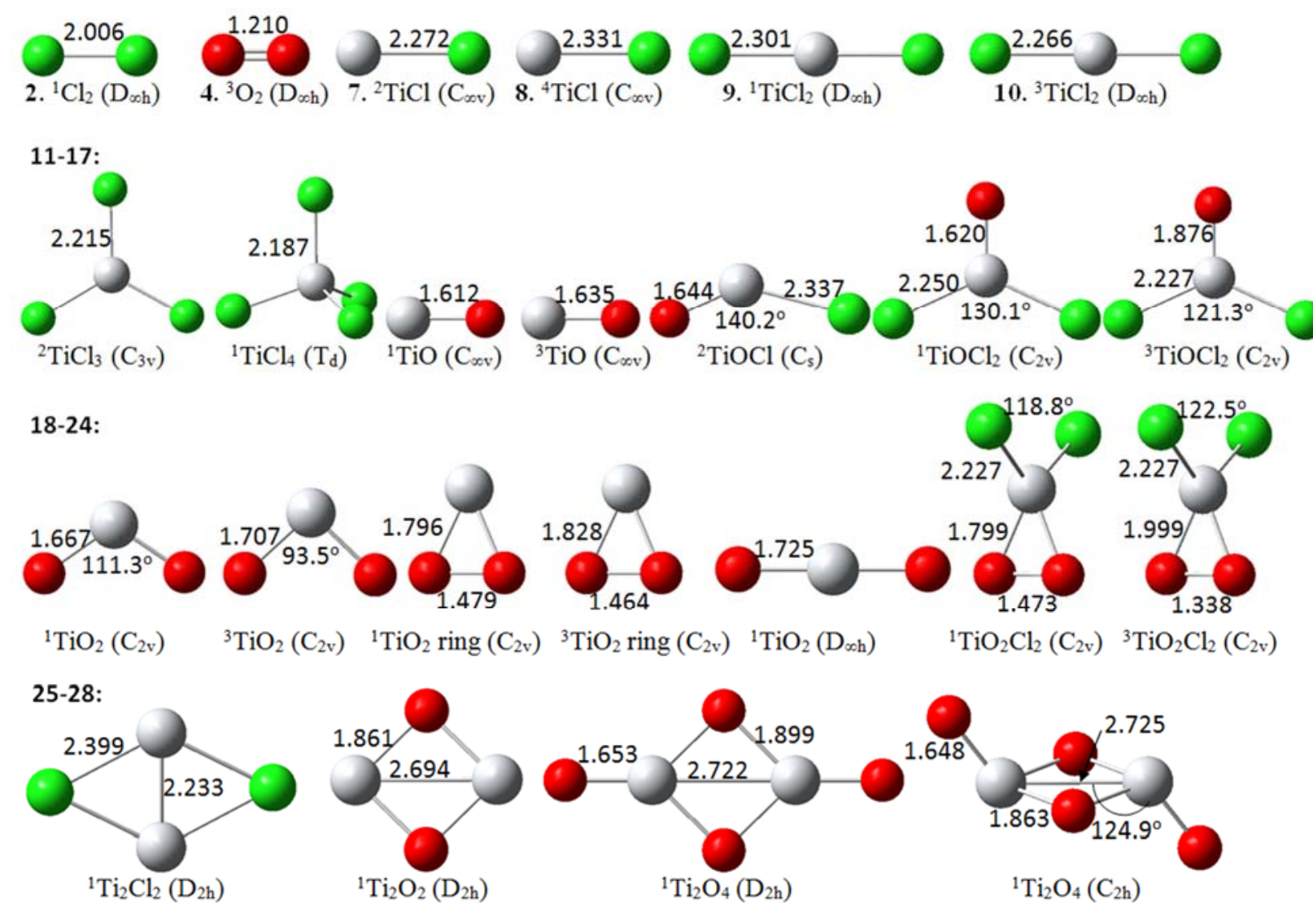

Figure 1. CR-CC(2,3)/cc-pVTZ optimized geometric parameters of the studied $\mathrm{Ti}_{x} \mathrm{O}_{y} \mathrm{Cl}_{z}$ species. Grey, red, and green spheres are $\mathrm{Ti}, \mathrm{O}$, and $\mathrm{Cl}$ atoms, respectively. Although 28 species are calculated and sorted by the numbers of $\mathrm{Ti}, \mathrm{O}$, and $\mathrm{Cl}$ atoms, in that order, only 24 structures are illustrated because species $1,3,5$, and 6 are ${ }^{2} \mathrm{Cl},{ }^{3} \mathrm{O},{ }^{1} \mathrm{Ti}$, and ${ }^{3} \mathrm{Ti}$ atoms. Each molecular structure is labeled with its molecule formula, multiplicity, and point group.

The CR-CC(2,3)/cc-pVTZ vibrational frequencies are also compared with experimental ones. ${ }^{8}$ The CR-CC $(2,3)$ vibrational frequencies of $\mathrm{Cl}_{2}$ and ${ }^{3} \mathrm{O}_{2}$ are 553 and $1600 \mathrm{~cm}^{-1}$, very close to the experimentally determined 560 and $1580 \mathrm{~cm}^{-1} .{ }^{8}$ The $\mathrm{CR}-\mathrm{CC}(2,3)$ and experimental vibrational frequency of ${ }^{4} \mathrm{TiCl}$ are 374 and $379.7 \mathrm{~cm}^{-1},{ }^{8}$ differing by $6 \mathrm{~cm}^{-1}$. The $\mathrm{CR}-\mathrm{CC}(2,3)$ vibrational frequencies of $\mathrm{TiCl}_{4}, 114(\mathrm{e}), 134\left(\mathrm{t}_{2}\right), 386\left(\mathrm{a}_{1}\right)$, and $506\left(\mathrm{t}_{2}\right) \mathrm{cm}^{-1}$, are also in good 
agreement with experimental data $111(\mathrm{e}), 131\left(\mathrm{t}_{2}\right), 368\left(\mathrm{a}_{1}\right)$, and $498.5\left(\mathrm{t}_{2}\right) \mathrm{cm}^{-1} .8$

Despite the neglect of the core-valence correlation (CV), scalar relativistic (SR) effects, and spin-orbit (SO) coupling, our CCSD(T)/CBS atomization energy is very close to Dixon et al.'s $\mathrm{CCSD}(\mathrm{T})$ calculations ${ }^{13}$ that carefully included the aforementioned $\mathrm{CV}, \mathrm{SR}$, and SO corrections: our atomization energy of $\mathrm{TiCl}_{4}, \mathrm{TiOCl}_{2}$, and $\mathrm{TiO}_{2}$ are 1703,1550 , and $1238 \mathrm{~kJ} / \mathrm{mol}$, in good agreement with Dixon et al.'s 1706, 1548, and $1245 \mathrm{~kJ} / \mathrm{mol}^{13}$

To further assess the accuracy of our CCSD(T)/CBS energy calculations, the enthalpy of formation of various $\mathrm{Ti}_{x} \mathrm{O}_{y} \mathrm{Cl}_{z}$ species at $298 \mathrm{~K}$ were calculated and compared with available experimental data. For convenience, ${ }^{3} \mathrm{O}_{2}$ and $\mathrm{Cl}_{2}$ are chosen to be the $\mathrm{O}$-containing and $\mathrm{Cl}-$ containing references in the calculations of enthalpy of all $\mathrm{Ti}_{x} \mathrm{O}_{y} \mathrm{Cl}_{z}$ species. $\mathrm{TiOCl}_{2}$ is chosen to be the Ti-containing reference as in Kraft et al.'s paper. ${ }^{15}$ Because of the significant discrepancy between experiments, ${ }^{8-10}$ we derived $\Delta H_{f, \text { exp }}^{o}\left(\mathrm{TiOCl}_{2}\right)$ from all available experimental enthalpies. ${ }^{8-10}$ The enthalpy of a $\mathrm{Ti}_{x} \mathrm{O}_{y} \mathrm{Cl}_{z}$ species can be related to those of $\mathrm{TiOCl}_{2},{ }^{3} \mathrm{O}_{2}$ and $\mathrm{Cl}_{2}$ using the following balanced chemical equation:

$$
x \mathrm{TiOCl}_{2}+\frac{y-x}{2} \mathrm{O}_{2}+\frac{z-2 x}{2} \mathrm{Cl}_{2} \rightarrow \mathrm{Ti}_{x} \mathrm{O}_{y} \mathrm{Cl}_{z}
$$

Assuming the calculated enthalpy relative to the $\mathrm{TiOCl}_{2},{ }^{3} \mathrm{O}_{2}$ and $\mathrm{Cl}_{2}$ is close to experimental ones, $\Delta H_{f, \exp }^{o}\left(\mathrm{TiOCl}_{2}\right)$ can easily be derived using the following equation:

$$
\begin{aligned}
& H_{C C}^{o}\left(\mathrm{Ti}_{x} \mathrm{O}_{y} C l_{z}\right)-x H_{C C}^{o}\left(\mathrm{TiOCl}_{2}\right)-\frac{y-x}{2} H_{C C}^{o}\left(\mathrm{O}_{2}\right)-\frac{z-2 x}{2} H_{C C}^{o}\left(\mathrm{Cl}_{2}\right) \\
\cong & \Delta H_{f, \exp }^{o}\left(\mathrm{Ti}_{x} \mathrm{O}_{y} C l_{z}\right)-x \Delta H_{\text {exp }}^{o}\left(\mathrm{TiOCl}_{2}\right)
\end{aligned}
$$

where $H_{C C}^{o}$ is the sum of the CCSD(T)/CBS electronic energy and the CR-CC(2,3)/cc-pVTZ enthalpy correction at $298 \mathrm{~K}$. Note that $\Delta H_{f, \exp }^{o}\left({ }^{3} \mathrm{O}_{2}\right)$ and $\Delta H_{f, \exp }^{o}\left(\mathrm{Cl}_{2}\right)$ are zero at $298 \mathrm{~K}$. Equation 2 is rearranged to express $\Delta H_{f, \exp }^{o}\left(\mathrm{TiOCl}_{2}\right)$ in terms of the $\Delta H_{f, \exp }^{o}\left(\mathrm{Ti}_{x} \mathrm{O}_{y} \mathrm{Cl}_{z}\right)$ and 
couple-cluster enthalpies of $\mathrm{Ti}_{x} \mathrm{O}_{y} \mathrm{Cl}_{z}, \mathrm{TiOCl}_{2},{ }^{3} \mathrm{O}_{2}$, and $\mathrm{Cl}_{2}$ :

$$
\begin{aligned}
& x \Delta H_{f, \exp }^{o}\left(\mathrm{TiOCl}_{2}\right) \\
\cong & \Delta H_{f, \exp }^{o}\left(\mathrm{Ti}_{x} \mathrm{O}_{y} C l_{z}\right)-H_{C C}^{o}\left(\mathrm{Ti}_{x} \mathrm{O}_{y} C l_{z}\right)+x H_{C C}^{o}\left(\mathrm{TiOCl}_{2}\right)+\frac{y-x}{2} H_{C C}^{o}\left(\mathrm{O}_{2}\right) \\
+ & \frac{z-2 x}{2} H_{C C}^{o}\left(\mathrm{Cl}_{2}\right)
\end{aligned}
$$

The NIST compiled $\Delta H_{f, \text { exp }}^{o}$ of ${ }^{3} \mathrm{Ti},{ }^{4} \mathrm{TiCl},{ }^{3} \mathrm{TiCl}_{2},{ }^{2} \mathrm{TiCl}_{3}, \mathrm{TiCl}_{4},{ }^{3} \mathrm{TiO},{ }^{2} \mathrm{TiOCl}, \mathrm{TiOCl}_{2}$, and $\mathrm{TiO}_{2},{ }^{8}$ Hildenbrand's experimental data of ${ }^{4} \mathrm{TiCl},{ }^{3} \mathrm{TiCl}_{2},{ }^{2} \mathrm{TiCl}_{3},{ }^{9}$ and Yungman's compilation of ${ }^{3} \mathrm{TiCl}_{2}$ and ${ }^{3} \mathrm{TiO}$ data ${ }^{10}$ were used to calculate $\Delta H_{f, \text { exp }}^{o}\left(\mathrm{TiOCl}_{2}\right)$ in Table 3 . The mean value of $\Delta H_{f, \exp }^{o}\left(\mathrm{TiOCl}_{2}\right)$ is determined to be $-600.5 \mathrm{~kJ} / \mathrm{mol}$, which is very close to $-598 \pm$ $20 \mathrm{~kJ} / \mathrm{mol}$ calculated by Kraft et al..$^{12}$ and to $-593.3 \mathrm{~kJ} / \mathrm{mol}$ calculated by Dixon et al.. ${ }^{13}$ Taking the mean value of $-600.5 \mathrm{~kJ} / \mathrm{mol}$ as the enthalpy of formation for $\mathrm{TiOCl}_{2}$ at $298 \mathrm{~K}$, the standard enthalpies of all other $\mathrm{Ti}_{x} \mathrm{O}_{y} \mathrm{Cl}_{z}$ species were calculated using Eq. 2 and listed in the last column of Table 3 for comparison with experimental values. Despite the neglect of core-valence correlation, relativistic effect, and spin-orbit coupling, our calculated enthalpy of formation of $\mathrm{TiCl}_{4}$ and $\mathrm{TiO}_{2}(-753.4$ and $-288.3 \mathrm{~kJ} / \mathrm{mol})$ are in good agreement with Dixon et al.'s calculations $(-759.4$ and $-283.7 \mathrm{~kJ} / \mathrm{mol})$ that carefully include those corrections. ${ }^{13}$

\begin{tabular}{|c|c|c|c|c|}
\hline & $\begin{array}{c}\text { Electronic } \\
\text { state }\end{array}$ & $\Delta H_{f, \text { exp }}^{o}{ }^{\mathrm{a}}$ & $\Delta H_{f}^{o}\left(\mathrm{TiOCl}_{2}\right)^{\mathrm{b}}$ & $\Delta H_{f, c c}^{o}{ }^{\mathrm{c}}$ \\
\hline${ }^{3} \mathrm{Ti}$ & ${ }^{3} \mathrm{~F}_{2}$ & $473.6 \pm 16.7$ & -588.1 & 461.1 \\
\hline${ }^{4} \mathrm{TiCl}$ & ${ }^{4} \Sigma_{g}$ & $\begin{array}{c}154 \pm 42 \\
(171.1 \pm 8.4)\end{array}$ & $\begin{array}{l}-634.2 \\
-617.0\end{array}$ & 187.6 \\
\hline${ }^{3} \mathrm{TiCl}_{2}$ & ${ }^{3} \Delta \mathrm{g}$ & $\begin{array}{c}-237.2 \pm 8.4 \\
(-205.0 \pm 8.4) \\
\{-238.5 \pm 12.6\}\end{array}$ & $\begin{array}{l}-618.1 \\
-585.9 \\
-619.4\end{array}$ & -219.7 \\
\hline
\end{tabular}

Table 3. Experimental standard enthalpy of formation of $\mathrm{Ti}_{x} \mathrm{O}_{y} \mathrm{Cl}_{z}$ species and our derived standard enthalpy of formation for $\mathrm{TiOCl}_{2}$ at $298 \mathrm{~K}$. All numbers are in $\mathrm{kJ} / \mathrm{mol}$. 


\begin{tabular}{lcccr}
\hline${ }^{2} \mathrm{TiCl}_{3}$ & ${ }^{2} \mathrm{~A}_{1}$ & $-539.3 \pm 6.3$ & -618.1 & \\
\cline { 3 - 4 } & & $(-508.4 \pm 8.4)$ & -587.1 & -521.8 \\
\hline $\mathrm{TiCl}_{4}$ & ${ }^{1} \mathrm{~A}_{1}$ & $-763.2 \pm 3.8$ & -610.4 & -753.4 \\
\hline${ }^{3} \mathrm{TiO}$ & ${ }^{3} \Delta$ & $\{54.4 \pm 8.4\}$ & -603.8 & 5 \\
\cline { 3 - 5 } & & $57.3 \pm 9.2$ & -600.9 & 57.7 \\
\hline${ }^{2} \mathrm{TiOCl}$ & ${ }^{2} \mathrm{~A}^{\prime}$ & -244 & -561.0 & -283.5 \\
\hline $\mathrm{TiOCl}_{2}$ & ${ }^{1} \mathrm{~A}_{1}$ & -546 & -546.0 & -600.5 \\
\hline $\mathrm{TiO}_{2}$ & ${ }^{1} \mathrm{~A}_{1}$ & $-305.4 \pm 12.6$ & -617.6 & -288.3 \\
\hline
\end{tabular}

${ }^{a}$ Experimental data enclosed in parenthesis and curly brackets are taken from Hildenbrand's paper $^{9}$ and from Yungman's compilation ${ }^{10}$, respectively. All other experimental data are taken from the NIST database. ${ }^{8}$

${ }^{\mathrm{b}}$ Calculated using Eq. 3. The mean value of the 14 derived $\Delta H_{f}^{o}\left(\mathrm{TiOCl}_{2}\right)$ is $-600.5 \mathrm{~kJ} / \mathrm{mol}$. ${ }^{\mathrm{c}}$ Calculated using Eq. 2 assuming $\Delta H_{f}^{o}\left(\mathrm{TiOCl}_{2}\right)=-600.5 \mathrm{~kJ} / \mathrm{mol}$ (this work) at $298 \mathrm{~K}$.

The CR-CC (2,3)/cc-pVTZ molecular geometries and frequencies, the CCSD(T)/aug-cc$\mathrm{pVLZ}(L=3-5)$ single-point and extrapolated CBS energies, the thermal corrections of the standard enthalpies of formation, the values of the entropy and heat capacity of all studied $\mathrm{Ti}_{x} \mathrm{O}_{y} \mathrm{Cl}_{z}$ species at $0-3000 \mathrm{~K}$ are included in Supplemental Material.

\subsection{Assessing the accuracy of the DFT energies}

Figure 2a illustrates the mean absolute deviation (MAD) and mean signed deviation (MSD) of DFT/6-311+G(d) atomization energies against the CCSD(T)/CBS//CR-CC(2,3)/cc-pVTZ benchmark. The atomization energy of the $\mathrm{Ti}_{x} \mathrm{O}_{y} \mathrm{Cl}_{z}$ species uses the ground electronic states of the ${ }^{3} \mathrm{Ti},{ }^{3} \mathrm{O}$, and ${ }^{2} \mathrm{Cl}$ atoms as zero references. 

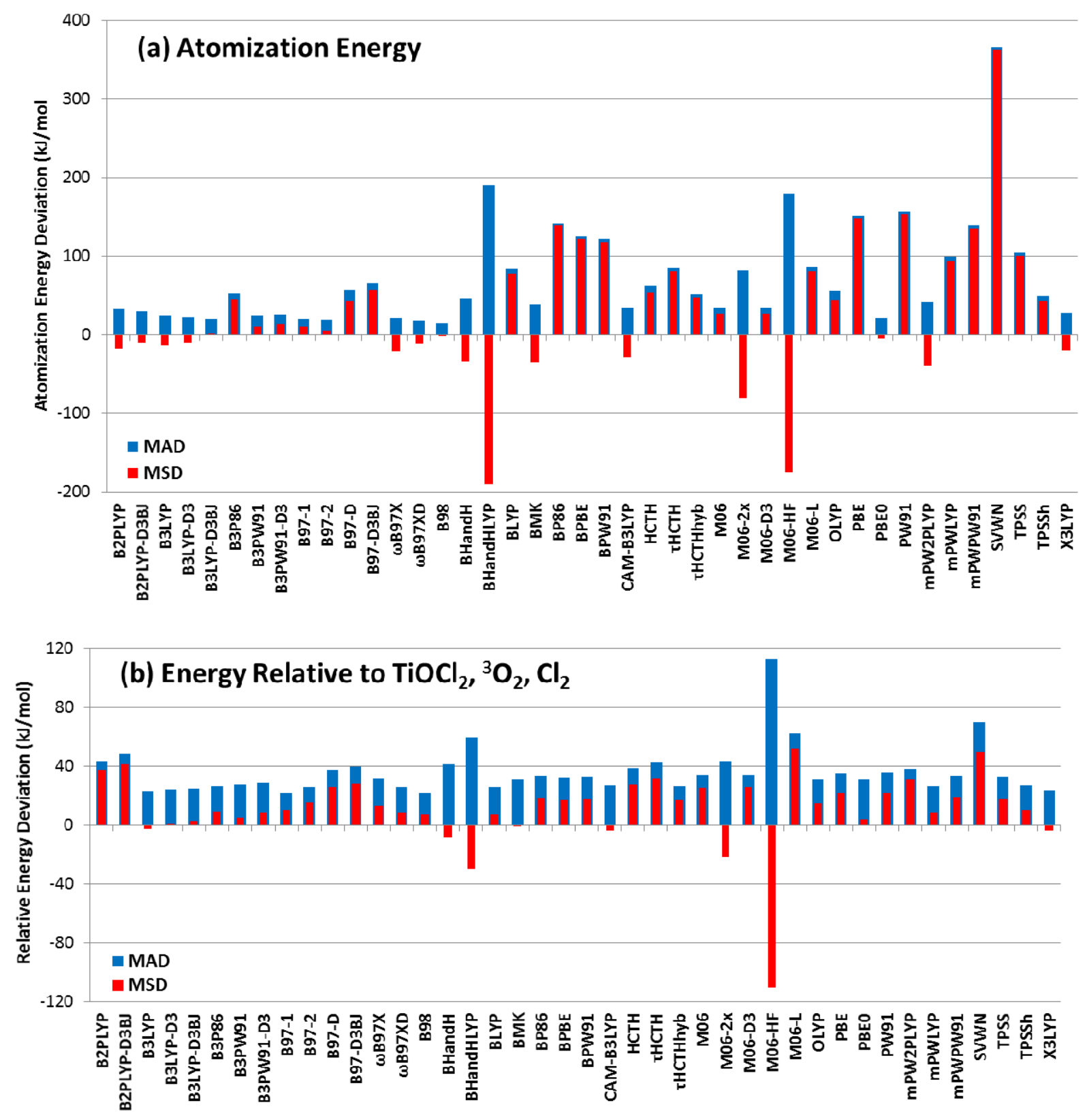

Figure 2. (a) Mean absolute deviations (blue bars) and mean signed deviations (red bars) calculated energies relative to ${ }^{3} \mathrm{Ti},{ }^{3} \mathrm{O}$, and ${ }^{2} \mathrm{Cl}$. (b) Mean absolute deviations (blue bars) and mean signed deviations (red bars) of calculated energy relative to $\mathrm{TiOCl}_{2},{ }^{3} \mathrm{O}_{2}$, and, $\mathrm{Cl}_{2}$. $\mathrm{The}$ $\mathrm{CCSD}(\mathrm{T}) / \mathrm{CBS} / / \mathrm{CR}-\mathrm{CC}(2,3) / \mathrm{cc}-\mathrm{pVTZ}$ energies are taken as the benchmark. 
Five assessed methods have a MAD of atomization energy below $20 \mathrm{~kJ} / \mathrm{mol}$ : B98 (15), $\omega B 97 X-D$ (18), B97-2 (18), B3LYP-D3BJ (19), and B97-1 (19); the numbers enclosed in parentheses are the corresponding MADs in $\mathrm{kJ} / \mathrm{mol}$. Five other methods have a slightly larger MAD between 20 and $25 \mathrm{~kJ} / \mathrm{mol}$ : PBE0, $\omega$ B97X, B3LYP-D3, B3PW91 and B3LYP. Note that these ten most accurate density functionals are all hybrid ones containing 20-25\% Hartree-Fock (HF) exchange except for $\omega \mathrm{B} 97 \mathrm{X}(16 \% \mathrm{HF}$ exchange). The density functionals with either higher or lower HF exchange perform significantly worse: BHandHLYP, M06-2X, and M06-HF (with $50 \%, 54 \%$, and $100 \%$ HF exchange) severely underbind with a MSD of $-191,-81$, and -175 $\mathrm{kJ} / \mathrm{mol}$, respectively; meanwhile, pure DFT methods with 0\% HF exchange such as BP86, BPBE, BPW91, PBE, and PW91 methods overbind by more than $120 \mathrm{~kJ} / \mathrm{mol}$. We may conclude that, among the pure and hybrid density functionals, the inclusion of $20-25 \%$ HF exchange works the best for the $\mathrm{Ti}_{x} \mathrm{O}_{y} \mathrm{Cl}_{z}$ species. Furthermore, we find the inclusion of the MP2-type correlation unsuitable for the $\mathrm{Ti}_{x} \mathrm{O}_{y} \mathrm{Cl}_{z}$ species as the B2PLYP and mPW2PLYP double-hybrid methods both perform poorly with MADs of 33 and $42 \mathrm{~kJ} / \mathrm{mol}$, respectively.

We also evaluated the accuracy of the DFT/6-311+G(d) energy calculations via comparison of energies relative to $\mathrm{TiOCl}_{2},{ }^{3} \mathrm{O}_{2}$, and $\mathrm{Cl}_{2}$. Taking the $\mathrm{TiOCl}_{2},{ }^{3} \mathrm{O}_{2}$, and $\mathrm{Cl}_{2}$ molecules instead of the ${ }^{3} \mathrm{Ti},{ }^{3} \mathrm{O}$, and ${ }^{2} \mathrm{Cl}$ atoms as the zero references for computing the relative energies, the MAD of many DFT methods decreases significantly (Figure 2b). However, only six DFT methods now have smaller than 25 kJ/mol MAD: B98 (22), B97-1 (22), B3LYP (23), X3LYP (24), B3LYP-D3 (24), and B3LYP-D3BJ (25). Ten more methods have a MAD below 30 kJ/mol: CAM-B3LYP, B3P86, B3PW91, B3PW91-D3, B97-2, wB97X-D, BLYP, mPWLYP, $\tau$-HCTHhyb, and TPSSh. Most of the top sixteen methods include $20-25 \%$ HF exchange. The density functionals with $\geq 50 \% \mathrm{HF}$ exchange such as BHandHLYP, B06-2X, and M06-HF have 
the most negative MSD of $-30,-21$ and $-111 \mathrm{~kJ} / \mathrm{mol}$, respectively. Pure DFT methods such as BP86, BPBE, BPW91, PBE, and PW91 methods have a positive MSD of 32-36 kJ/mol. Overall, when $\mathrm{TiOCl}_{2},{ }^{3} \mathrm{O}_{2}$, and $\mathrm{Cl}_{2}$ are taken as zero references, DFT methods with moderate $20-25 \%$ exact HF exchange still perform better than those with $0 \%$ or $\geq 50 \%$ HF exchange. The doublehybrid methods again perform poorly: both B2PLYP and mPW2PLYP have a large MAD of $\sim 40$ $\mathrm{kJ} / \mathrm{mol}$.

We then take the average (denoted $\overline{\mathrm{MAD}}$ ) of the MAD of energies relative to ${ }^{3} \mathrm{Ti},{ }^{3} \mathrm{O}$, and ${ }^{2} \mathrm{Cl}$ atoms and the MAD of energies relative to $\mathrm{TiOCl}_{2},{ }^{3} \mathrm{O}_{2}$, and $\mathrm{Cl}_{2}$. Seven DFT methods have a $\overline{\text { MAD }}$ smaller than 25 kJ/mol: B98 (18), B97-1 (21), B97-2 (22), B3LYP-D3BJ (22), wB97X-D (22), B3LYP-D3 (23), and B3LYP (24). These seven methods fall into either the B97 family (B97-1, B97-2, $\omega$ B97X-D, and B98) or the B3LYP family (B3LYP, B3LYP-D3, and B3LYPD3BJ), all with $20-25 \%$ HF exchange. Note that our top choice B98 is also ranked the most accurate by Wilson et al. for a mostly different set of Ti-containing molecules. ${ }^{16-18}$

Because none of the test molecules contains significant dispersion, the inclusion of empirical dispersion has little effect on the accuracy of the assessed density functionals: B3LYPD3BJ and B3LYP-D3 have 1-2 kJ/mol smaller $\overline{\text { MAD }}$ than B3LYP; $\omega$ B97X-D has $~ 5 \mathrm{~kJ} / \mathrm{mol}$ smaller $\overline{\mathrm{MAD}}$ than $\omega \mathrm{B} 97 \mathrm{X}$; M06-D3 and M06 have essentially the same $\overline{\mathrm{MAD}}$ (33.8 vs 33.7 $\mathrm{kJ} / \mathrm{mol}$ ); B3PW91-D3 has $1 \mathrm{~kJ} / \mathrm{mol}$ greater $\overline{\mathrm{MAD}}$ than B3PW91. Although the inclusion of empirical dispersion is important for larger systems such as bulk $\mathrm{TiO}_{2}$ structures, ${ }^{76,77}$ it is much less so for the small species.

To further analyze the source of energy errors, additional B98 optimization calculations were carried out using various basis sets. The B98 method with the 6-31G(d), 6-31+G(d), and 6$311+\mathrm{G}(2 \mathrm{df})$ basis sets yield $\overline{\mathrm{MAD}} \mathrm{s}$ of $25.5,18.7$, and $18.8 \mathrm{~kJ} / \mathrm{mol}$, respectively, which shows the 
$6-311+\mathrm{G}(\mathrm{d})$ basis set $(\mathrm{B} 98 \overline{\mathrm{MAD}}=18.4 \mathrm{~kJ} / \mathrm{mol})$ well balances computational cost and accuracy. B98/6-311+G(d) single-point energies were also computed at the benchmark CR-CC $(2,3)$ geometries. The B98//CR-CC $(2,3) \overline{\mathrm{MAD}}(19.2 \mathrm{~kJ} / \mathrm{mol})$ is close to the $18.4 \mathrm{~kJ} / \mathrm{mol} \overline{\mathrm{MAD}}$ of B98/6$311+\mathrm{G}(\mathrm{d})$ optimization calculations; the differences between the B98 and benchmark coupledcluster geometries have little effect in the relative energy accuracy.

Having analyzed the effects of basis sets and geometries in the DFT energy calculations, we suggest the dominant source of error resides in the exchange and correlation functionals, particularly in the exchange functionals. Our atomization energy calculations show that pure DFT methods overbind. It is because the unphysical self-interaction error in pure density functionals overestimates the relative energy of high-spin states such as the ${ }^{3} \mathrm{Ti}$ and ${ }^{3} \mathrm{O},{ }^{30,78}$ which consequently results in greater atomization energies of the $\mathrm{Ti}_{x} \mathrm{O}_{y} \mathrm{Cl}_{z}$ species. Conversely, HF underestimates the relative energy of high-spin states. ${ }^{30,78}$ As a result, hybrid GGAs with large $\mathrm{HF}$ exchange underestimate the $\mathrm{Ti}_{x} \mathrm{O}_{y} \mathrm{Cl}_{z}$ atomization energies. To examine the errors from only the exchange functionals, we compare the BLYP, B3LYP, and BHandHLYP methods, which contain different $0 \%, 20 \%$, and $50 \% \mathrm{HF}$ exchange but the same LYP correlation functional; their MSD of atomization energies are 77, -14 , and $-191 \mathrm{~kJ} / \mathrm{mol}$, respectively. The trend is clear that the MSD decreases as the percentage of HF exchange increases. The same trend is observed for the M06-L, M06, M06-2X, and M06-HF functionals with 0\%, 27\%, 54\%, and $100 \% \mathrm{HF}$ exchange; their MSDs of atomization energy are $81,27,-81,-175 \mathrm{~kJ} / \mathrm{mol}$, respectively. When $\mathrm{TiOCl}_{2},{ }^{3} \mathrm{O}_{2}$, and $\mathrm{Cl}_{2}$ replace the ${ }^{3} \mathrm{Ti},{ }^{3} \mathrm{O}$, and ${ }^{2} \mathrm{Cl}$ references in the relative energy calculations, similar dependence of energy errors on the HF exchange is observed due to the high-spin ${ }^{3} \mathrm{O}_{2}$ reference. The dependence, however, is to a lesser extent because the high-spin ${ }^{3} \mathrm{Ti}$ reference is replaced by the singlet $\mathrm{TiOCl}_{2}$ molecule. 
In sum, the hybrid DFT methods with moderate $20-25 \%$ HF exchange are the most accurate for the energy prediction of the $\mathrm{Ti}_{x} \mathrm{O}_{y} \mathrm{Cl}_{z}$ species. More specifically, the $\mathrm{B} 98$ and $\mathrm{B} 97-1$ are the two best choices for the $\mathrm{Ti}_{x} \mathrm{O}_{y} \mathrm{Cl}_{z}$ species. B97-2 has accuracy similar to B97-1 in energy calculations but has much greater MAD in bond lengths (see subsection 3.3). The performance of the B3LYP method, although slightly behind B98 and B97-1, is also quite satisfactory.

\subsection{Assessing the accuracy of the DFT predicted geometric parameters}

The accuracy of the DFT/6-311+G(d) bond distances were assessed against the CR-CC $(2,3) / \mathrm{cc}-$ pVTZ benchmark data (Figure 3a). All 42 DFT methods have a negative mean signed deviation (MSD) which indicates that DFT in general underestimates the bond distances for the $\mathrm{Ti}_{x} \mathrm{O}_{y} \mathrm{Cl}_{z}$ species. B2PLYP, B2PLYP-D3BJ, and mPW2PLYP have the smallest mean absolute deviations (MAD) of $0.02 \AA$ or less. The better performance of these double-hybrid functionals originates from the fortuitous cancelation between the overestimate by DFT and the underestimate by MP2. Four assessed hybrid DFT methods have rather small MAD under $0.025 \AA$ : B3LYP $(0.024 \AA)$,

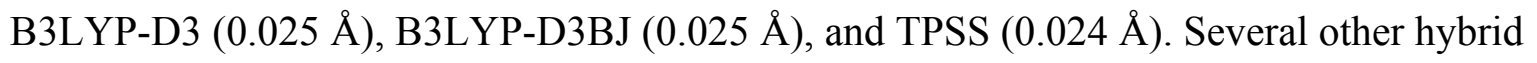
functionals have an acceptable MAD around 0.025-0.03 $\AA$, which include B97-1 (0.027 $\AA$ ) and B98 (0.029 $\AA)$, the two most accurate methods for energy calculations. Most pure DFT methods also have small MADs less than $0.03 \AA$. Although B97-2 is nearly as accurate as B97-1 in energy prediction, it has a much larger $0.037 \AA$ MAD in bond lengths. Only two assessed density functionals have a MAD greater than $0.04 \AA$ : BHandH $(0.057 \AA)$ and SVWN $(0.058 \AA)$; their MSD's are both $-0.057 \AA$. SVWN is well known to overbind and underestimate bond lengths. ${ }^{79}$ BHandH also has a large negative MSD in bond lengths partly due to its inclusion of 50\% $\mathrm{HF}$ exchange and 50\% LSDA exchange. 

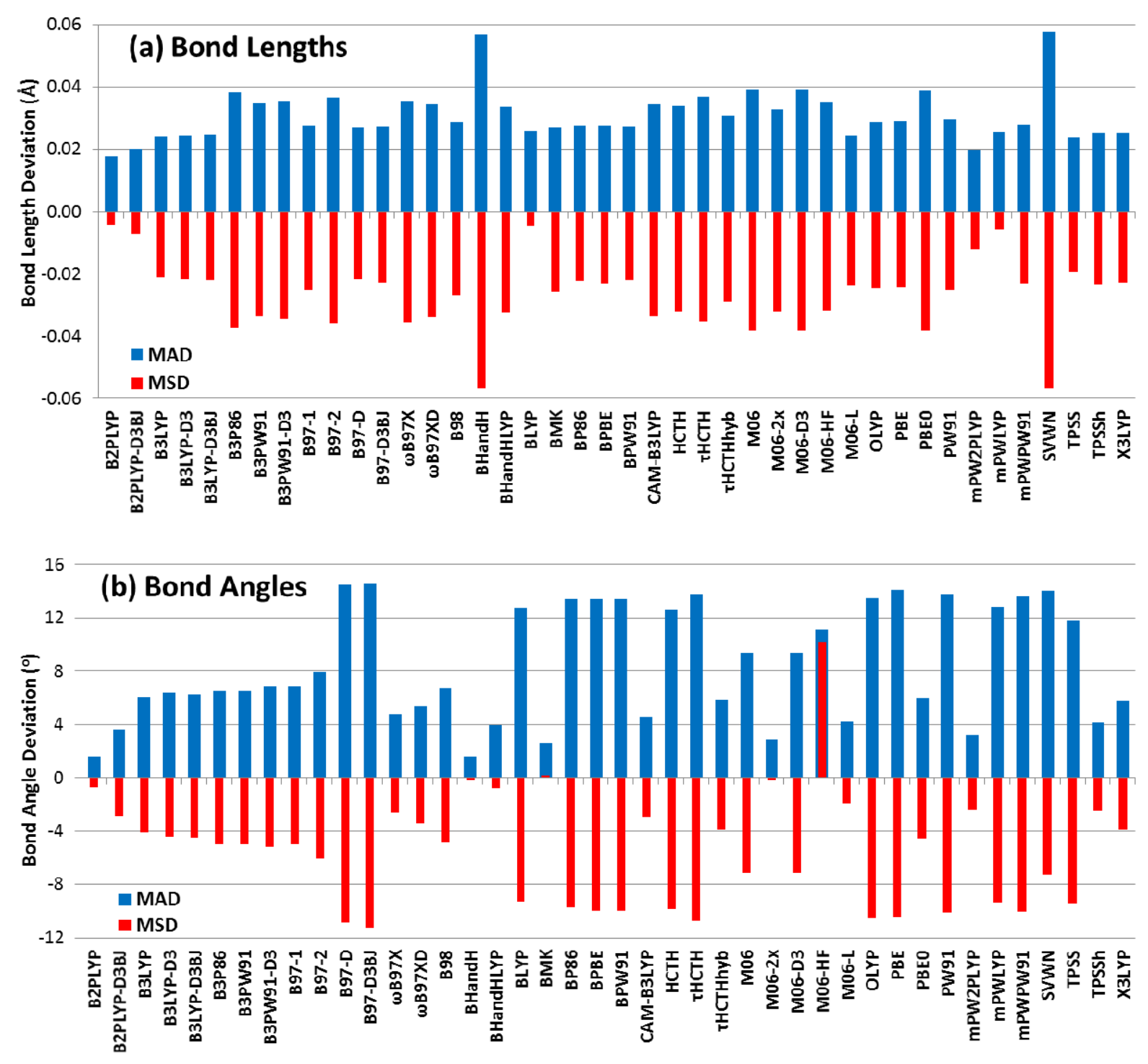

Figure 3. (a) Mean absolute deviations (blue bars) and mean signed deviations (red bars) of calculated bond distances. (b) Mean absolute deviations (blue bars) and mean signed deviations (red bars) of calculated bond angles. The CR-CC(2,3)/cc-pVTZ geometric parameters are taken as the benchmark.

Ten bond angles are used to assess the accuracy of the DFT methods (Figure 3b): the 
bond angles of ${ }^{1} \mathrm{TiCl}_{2}$ and ${ }^{3} \mathrm{TiCl}_{2}$, the $\mathrm{Cl}-\mathrm{Ti}-\mathrm{O}$ angle in ${ }^{2} \mathrm{TiOCl}$, the $\mathrm{Cl}-\mathrm{Ti}-\mathrm{Cl}$ angle in ${ }^{1} \mathrm{TiOCl}_{2}$,

${ }^{3} \mathrm{TiOCl}_{2},{ }^{1} \mathrm{TiO}_{2} \mathrm{Cl}_{2}$, and ${ }^{3} \mathrm{TiO}_{2} \mathrm{Cl}_{2}$, the O-Ti-O angle in the bent structures of ${ }^{1} \mathrm{TiO}_{2}$ and ${ }^{3} \mathrm{TiO}_{2}$, and the Ti-Ti-O angle in $\mathrm{Ti}_{2} \mathrm{O}_{4}$. The benchmark $\mathrm{CR}-\mathrm{CC}(2,3)$ bond angles are given in Figure 1. Besides having the smallest MADs in bond lengths, the B2PLYP and mPW2PLYP doublehybrid methods also have small MADs of bond angles: $1.6^{\circ}$ and $3.2^{\circ}$ (Figure 3b). The B98, B971, and B3LYP methods have fairly large MADs of $6.7^{\circ}, 6.8^{\circ}$ and $6.0^{\circ}$ because they all erroneously predict the ${ }^{1} \mathrm{TiCl}_{2}$ and ${ }^{3} \mathrm{TiCl}_{2}$ structures to be bent while both experiments ${ }^{8}$ and our CR-CC $(2,3)$ calculations suggest they be linear. After excluding the errors of ${ }^{1} \mathrm{TiCl}_{2}$ and ${ }^{3} \mathrm{TiCl}_{2}$, the MADs of B98, B97-1, and B3LYP methods are reduced to $2.7^{\circ}, 2.8^{\circ}$, and 3.1 ${ }^{\circ}$. Pure DFT methods perform poorly with a MAD of bond angles greater than $10^{\circ}$ due to their large errors in the bond angles of ${ }^{1} \mathrm{TiCl}_{2},{ }^{3} \mathrm{TiCl}_{2}$, and ${ }^{2} \mathrm{TiOCl}$.

In general, the double-hybrid DFT methods are more accurate in the prediction of bond lengths and angles than the hybrid DFT ones, which are in turn more accurate than the pure DFT methods. More specifically, we recommend using the B2PLYP and mPW2PLYP functionals if acquiring accurate geometric parameters for $\mathrm{Ti}_{x} \mathrm{O}_{y} \mathrm{Cl}_{z}$ species is of the most importance.

\subsection{Assessing the accuracy of the DFT predicted enthalpy and Gibbs energy at finite temperatures}

Because the flame synthesis of $\mathrm{TiO}_{2}$ nanoparticles occurs at high temperatures, we assessed the performance of selected DFT methods concerning their performance in the prediction of enthalpy and Gibbs energy at temperatures up to $3000 \mathrm{~K}$. Six DFT methods, B3LYP, B3LYPD3BJ, B97-1, B97-2, $\omega \mathrm{B} 97 \mathrm{X}-\mathrm{D}$, and B98, were chosen for the assessment because they have overall better performance than others, especially in the prediction of energies. Figure 4a shows 
the $\overline{\mathrm{MAD}}$ of enthalpy has little dependence on the temperature. B98 remains the most accurate method (with $\overline{\mathrm{MAD}}=18.3-18.8 \mathrm{~kJ} / \mathrm{mol}$ ) in the whole $0-3000 \mathrm{~K}$ temperature range; $\mathrm{B} 97-1$ ranks second with a $\overline{\mathrm{MAD}}$ of 20.2-20.6 kJ/mol. The B97-2, B3LYP, and B3LYP-D3BJ calculations are also fairly accurate with a $\overline{\mathrm{MAD}}$ of approximately 22,24 , and $22 \mathrm{~kJ} / \mathrm{mol}$, respectively, at all temperatures. $\omega \mathrm{B} 97 \mathrm{X}-\mathrm{D}$ has a reasonable $\overline{\mathrm{MAD}}$ of $22 \mathrm{~kJ} / \mathrm{mol}$ at the room temperature but this $\overline{\mathrm{MAD}}$ rapidly increases to $32 \mathrm{~kJ} / \mathrm{mol}$ at $3000 \mathrm{~K}$, which makes it the least appealing for the calculation of $\mathrm{Ti}_{x} \mathrm{O}_{y} \mathrm{Cl}_{z}$ species at high temperatures.

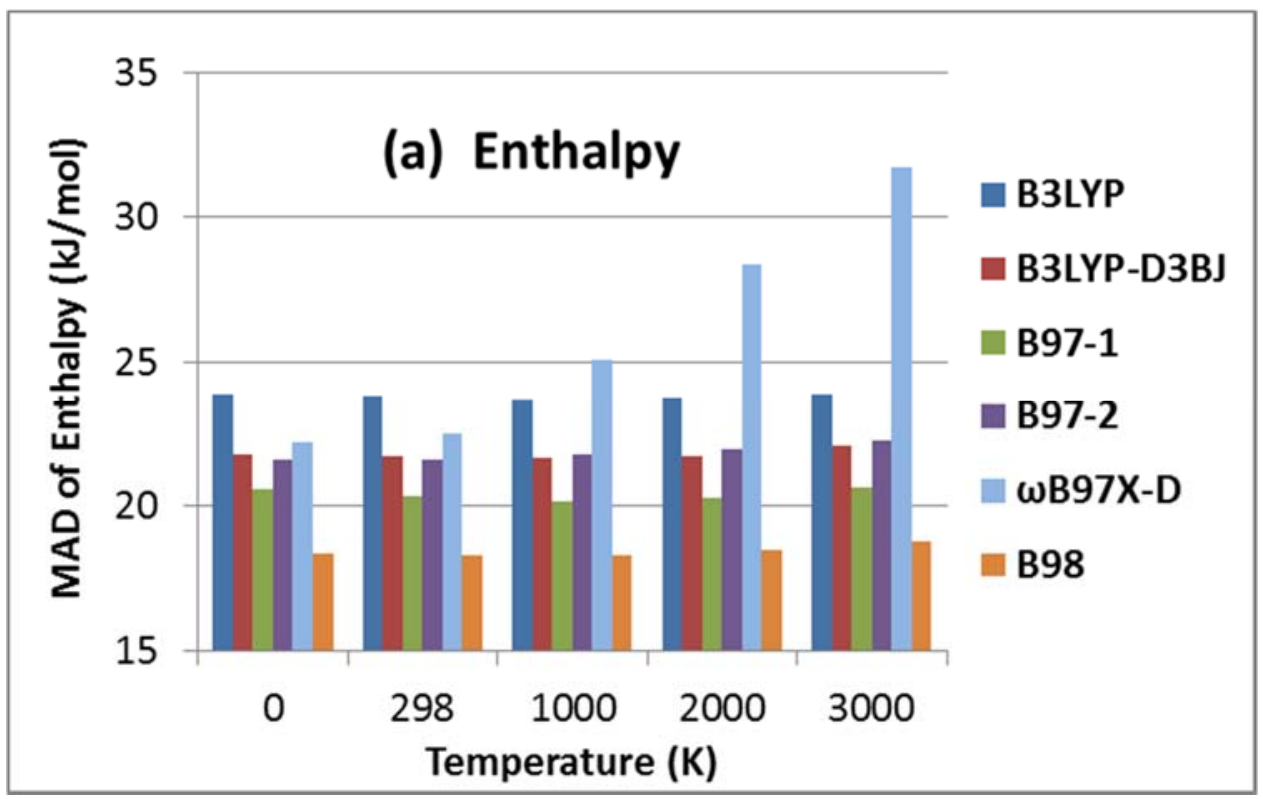




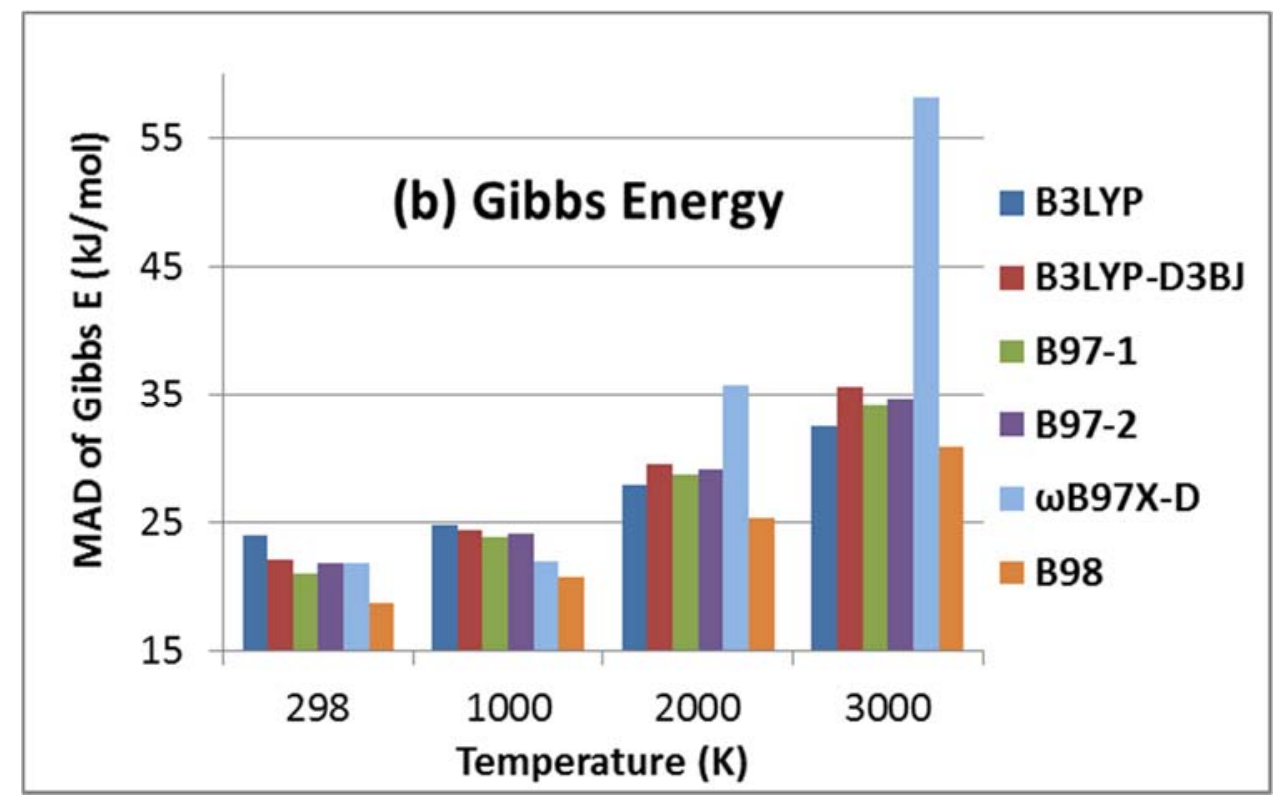

Figure 4. Mean absolute deviations of DFT calculated (a) enthalpy and (b) Gibbs energy.

Figure 4b shows that B98 is again the most accurate in Gibbs energy calculations; its $\overline{\mathrm{MAD}}$ of Gibbs energy is $19 \mathrm{~kJ} / \mathrm{mol}$ at $298 \mathrm{~K}$ and $31 \mathrm{~kJ} / \mathrm{mol}$ at $3000 \mathrm{~K}$. The larger $\overline{\mathrm{MAD}}$ of Gibbs energy at higher temperatures is due to the propagation of the errors in entropy. B3LYP, B3LYPD3BJ, B97-1, B97-2 are reasonably accurate with a 21-24 kJ/mol $\overline{\mathrm{MAD}}$ at $298 \mathrm{~K}$ and a larger 32$36 \mathrm{~kJ} / \mathrm{mol} \overline{\mathrm{MAD}}$ at $3000 \mathrm{~K}$. The $\omega \mathrm{B} 97 \mathrm{X}-\mathrm{D}$ has a reasonable $\overline{\mathrm{MAD}}$ of $22 \mathrm{~kJ} / \mathrm{mol}$ at $298 \mathrm{~K}$ but a much larger $58 \mathrm{~kJ} / \mathrm{mol} \overline{\mathrm{MAD}}$ at $3000 \mathrm{~K}$ due to its exceptionally large entropy errors. At temperatures between $1000 \mathrm{~K}$ and $2000 \mathrm{~K}$, which is a typical temperature range for the flame synthesis of $\mathrm{TiO}_{2}$ nanoparticle, the B3LYP, B97-1, and B98 $\overline{\text { MAD }}$ s of Gibbs energy are $25-28$ $\mathrm{kJ} / \mathrm{mol}, 24-29 \mathrm{~kJ} / \mathrm{mol}$, and $21-25 \mathrm{~kJ} / \mathrm{mol}$, respectively. These $\overline{\mathrm{MAD}} \mathrm{s}$ are small enough for the B3LYP, B97-1, and B98 methods to be used for making reasonably accurate prediction of the thermochemistry of the flame synthesis of $\mathrm{TiO}_{2}$ nanoparticles. 


\section{Conclusions}

We calculated the geometric parameters and vibrational frequencies at the CR-CC(2,3)/cc-pVTZ level of theory and then extrapolated the $\mathrm{CCSD}(\mathrm{T}) / \mathrm{CBS}$ energies for small $\mathrm{Ti}_{x} \mathrm{O}_{y} \mathrm{Cl}_{z}$ species. We derived $\Delta H_{f}^{o}\left(\mathrm{TiOCl}_{2}\right)$ to be $-600.5 \mathrm{~kJ} / \mathrm{mol}$ at $298 \mathrm{~K}$ from all available experimental data and coupled-cluster calculations; this value is in good agreement with previous calculations by Kraft et al. $(-598 \pm 20 \mathrm{~kJ} / \mathrm{mol})^{15}$ and Dixon et al. $(-593.3 \mathrm{~kJ} / \mathrm{mol})^{13}$. Although the core-valence correlation, relativistic effect, and spin-orbit coupling are not included, our coupled-cluster calculations are still in good agreement with calculations that include those corrections ${ }^{13}$ and also with experiments. ${ }^{8-10}$ Accurate thermochemical data for more than 20 small $\mathrm{Ti}_{x} \mathrm{O}_{y} \mathrm{Cl}_{z}$ species are calculated and used as benchmark for the assessment of 42 DFT methods for the $\mathrm{Ti}_{x} \mathrm{O}_{y} \mathrm{Cl}_{z}$ molecules. We find the density functionals with moderate $20-25 \% \mathrm{HF}$ exchange perform significantly better than the pure functionals and those with $\geq 50 \% \mathrm{HF}$ exchange for the $\mathrm{Ti}_{x} \mathrm{O}_{y} \mathrm{Cl}_{z}$ species. However, extending this statement to other transition metal compounds must be done with caution as suggested in Cramer and Truhlar's review of DFT methods and the references therein. ${ }^{78}$ In general, we recommend using methods from the B97 or B3LYP family for the energy prediction of the $\mathrm{Ti}_{x} \mathrm{O}_{y} \mathrm{Cl}_{z}$ species. In particular, the $\mathrm{B} 98$ method is highly recommended tightly followed by the B97-1 and B3LYP methods and their variations. The B98, B97-1, and B3LYP methods are also the most accurate in predicting enthalpy and Gibbs energy at high temperatures. We recommend using these three methods in thermochemical study of the $\mathrm{TiO}_{2}$ nanoparticles synthesis via the combustion of $\mathrm{TiCl}_{4}$ in oxygen.

Acknowledgements: Y. Ge thanks Central Washington University (CWU) Faculty Research Program and School of Graduate Studies and Research for their financial support to this work. Y. Ge also thanks the CWU Information Services for granting access to their high-performance 
computers and particularly thanks Bill Glessner for his technical assistance. K.-T. Lam thanks the CWU Office of Undergraduate Research for the Undergraduate Research Fellowship. 


\section{References}

(1) Mudunkotuwa IA, Grassian VH. The Devil Is in the Details (or the Surface): Impact of Surface Structure and Surface Energetics on Understanding the Behavior of Nanomaterials in the Environment. J. Environ. Monit. 13:1135-1144, 2011.

(2) Chen H, Nanayakkara CE, Grassian VH. Titanium Dioxide Photocatalysis in Atmospheric Chemistry. Chem. Rev. 112:5919-5948, 2012.

(3) Rhodes CJ. Reactive Radicals on Reactive Surfaces: Heterogeneous Processes in Catalysis and Environmental Pollution Control. Prog. React. Kinet. Mech. 30:145-213, 2005.

(4) Kamat P V. TiO 2 Nanostructures: Recent Physical Chemistry Advances. J. Phys. Chem. C 116:11849-11851, 2012.

(5) Zhang QF, Cao GZ. Nanostructured Photoelectrodes for Dye-Sensitized Solar Cells. Nano Today 6:91-109, 2011.

(6) Lee JK, Yang MJ. Progress in Light Harvesting and Charge Injection of Dye-Sensitized Solar Cells. Mater. Sci. Eng. B-Advanced Funct. Solid-State Mater. 176:1142-1160, 2011.

(7) Liu L, Chen X. Titanium Dioxide Nanomaterials: Self-Structural Modifications. Chem. Rev. 114:9890-9918, 2014.

(8) Chase MWJ. NIST-JANAF Thermochemical Tables. J. Phys. Chem. Ref. Data Monograph:1-1951, 1998.

(9) Hildenbrand DL. Low-Lying Electronic States and Revised Thermochemistry of TiCl, $\mathrm{TiCl}_{2}$, and $\mathrm{TiCl}_{3}$. J. Phys. Chem. A 113:1472-1474, 2009.

(10) Yungman V. Thermal Constants of Substances; Wiley: New York, 1999.

(11) Gordon JS. Astrosystems, Inc., Caldwell Twp., NJ, Personal Communication. 1963.

(12) West RH, Beran GJO, Green WH, Kraft M. First-Principles Thermochemistry for the Production of $\mathrm{TiO}_{2}$ from $\mathrm{TiCl}_{4}$. J. Phys. Chem. A 111:3560-3565, 2007.

(13) Wang T-H, Navarrete-Lopez AM, Li S, Dixon DA, Gole JL. Hydrolysis of TiCl4: Initial Steps in the Production of $\mathrm{TiO}_{2}$. J. Phys. Chem. A 114:7561-7570, 2010.

(14) Voter AF. Introduction to the Kinetic Monte Carlo Method. In Radiation Effects in Solids; Sickafus, K. E., Kotomin, E. A., Uberuaga, B. P., Eds.; Springer, NATO Publishing Unit: Dordrecht, 2005. 
(15) West RH, Celnik MS, Inderwildi OR, Kraft M, Beran GJO, Green WH. Toward a Comprehensive Model of the Synthesis of $\mathrm{TiO}_{2}$ Particles from TiCl4. Ind. Eng. Chem. Res. 46:6147-6156, 2007.

(16) Jiang W, DeYonker NJ, Determan JJ, Wilson AK. Toward Accurate Theoretical Thermochemistry of First Row Transition Metal Complexes. J. Phys. Chem. A 116:870$885,2012$.

(17) Jiang W, DeYonker NJ, Wilson AK. Multireference Character for 3d Transition-MetalContaining Molecules. J. Chem. Theory Comput. 8:460-468, 2012.

(18) Jiang W, Laury ML, Powell M, Wilson AK. Comparative Study of Single and Double Hybrid Density Functionals for the Prediction of 3d Transition Metal Thermochemistry. $J$. Chem. Theory Comput. 8:4102-4111, 2012.

(19) Li S, Dixon DA. Molecular Structures and Energetics of the $\left(\mathrm{TiO}_{2}\right)_{n}(\mathrm{n}=1-4)$ Clusters and Their Anions. J. Phys. Chem. A 112:6646-6666, 2008.

(20) Du H, Jia Y, Zhang R-Q. Stable Structures and Characteristic Vibrational Spectra of $\mathrm{TinO}_{\mathrm{m}}(\mathrm{n}=2-4 ; \mathrm{m}=1-2 \mathrm{n})$ Clusters. J. Theor. Comput. Chem. 12:1250094, 2013.

(21) Baboul AG, Schlegel HB. Structures and Energetics of Some Potential Intermediates in Titanium Nitride Chemical Vapor Deposition: $\mathrm{TiCl}_{\mathrm{m}}\left(\mathrm{NH}_{2}\right)_{\mathrm{n}}, \mathrm{TiCl}_{\mathrm{m}}\left(\mathrm{NH}_{2}\right)_{\mathrm{nNH}} \mathrm{N}$, and $\mathrm{TiCl}_{\mathrm{m}}\left(\mathrm{NH}_{2}\right)_{\mathrm{n}} \mathrm{N}$. An Ab Initio Molecular Orbital Study. J. Phys. Chem. B 102:5152-5157, 1998.

(22) Sousa SF, Fernandes PA, Ramos MJ. General Performance of Density Functionals. $J$. Phys. Chem. A 111:10439-10452, 2007.

(23) Piecuch P, Kucharski SA, Kowalski K, Musial M. Efficient Computer Implementation of the Renormalized Coupled-Cluster Methods: The R-CCSD[T], R-CCSD(T), CRCCSD[T], and CR-CCSD(T) Approaches. Comput. Phys. Commun. 149:71-96, 2002.

(24) Piecuch P, Wloch M. Renormalized Coupled-Cluster Methods Exploiting Left Eigenstates of the Similarity-Transformed Hamiltonian. J. Chem. Phys. 123:224105, 2005.

(25) Piecuch P, Wloch M, Gour JR, Kinal A. Single-Reference, Size-Extensive, Non-Iterative Coupled-Cluster Approaches to Bond Breaking and Biradicals. Chem. Phys. Lett. 418:467-474, 2006.

(26) Wloch M, Gour JR, Piecuch P. Extension of the Renormalized Coupled-Cluster Methods Exploiting Left Eigenstates of the Similarity-Transformed Hamiltonian to Open-Shell Systems: A Benchmark Study. J. Phys. Chem. A 111:11359-11382, 2007. 
(27) Ge Y, Gordon MS, Piecuch P, Włoch M, Gour JR. Breaking Bonds of Open-Shell Species with the Restricted Open-Shell Size Extensive Left Eigenstate Completely Renormalized Coupled-Cluster Method. J. Phys. Chem. A 112:11873-11884, 2008.

(28) Ge Y, Gordon MS, Piecuch P. Breaking Bonds with the Left Eigenstate Completely Renormalized Coupled-Cluster Method. J. Chem. Phys. 127:174106, 2007.

(29) Karton A, Martin JML. Comment on: "Estimating the Hartree-Fock Limit from Finite Basis Set Calculations" [Jensen F (2005) Theor Chem Acc 113, 267]. Theor. Chem. Acc. 115:330-333, 2006.

(30) Jensen F. Introduction to Computational Chemistry, 2nd ed.; John Wiley \& Sons Ltd: West Sussex, 2007.

(31) Gordon MS, Schmidt MW. Advances in Electronic Structure Theory: GAMESS a Decade Later. In Theory and Applications of Computational Chemistry, Ch. 41; Dykstra, C. E., Frenking, G., Kim, K. S., Scuseria, G. E., Eds.; Elsevier, 2005.

(32) Schmidt MW, Baldridge KK, Boatz JA, Elbert ST, Gordon MS, Jensen JH, Koseki S, Matsunaga N, Nguyen KA, Su SJ, Windus TL, Dupuis M, Montgomery JA. General Atomic and Molecular Electronic-Structure System. J. Comput. Chem. 14:1347-1363, 1993.

(33) Gaussian 09, Revision D.1, M. J. Frisch, Et. A1., Gaussian, Inc., Wallingford CT. 2009.

(34) Grimme S, Antony J, Ehrlich S, Krieg H. A Consistent and Accurate Ab Initio Parametrization of Density Functional Dispersion Correction (DFT-D) for the 94 Elements H-Pu. J. Chem. Phys. 132:154104, 2010.

(35) Grimme S, Ehrlich S, Goerigk L. Effect of the Damping Function in Dispersion Corrected Density Functional Theory. J. Comput. Chem. 32:1456-1465, 2011.

(36) Hohenberg P, Kohn W. Inhomogeneous Electron Gas. Phys. Rev. 136:B864-B871, 1964.

(37) Kohn W, Sham LJ. Self-Consistent Equations Including Exchange and Correlation Effects. Phys. Rev. 140:A1133-A1138, 1965.

(38) Slater JC. The Self-Consistent Field for Molecular and Solids, Quantum Theory of Molecular and Solids Volume 4. (Pure \& Applied Physics); McGraw-Hill: New York, 1974.

(39) Vosko SH, Wilk L, Nusair M. Accurate Spin-Dependent Electron Liquid Correlation Energies for Local Spin Density Calculations: A Critical Analysis. Can. J. Phys. 58:1200$1211,1980$. 
(40) Grimme S. Semiempirical Hybrid Density Functional with Perturbative Second-Order Correlation. J. Chem. Phys. 124:034108, 2006.

(41) Becke AD. Density-Functional Thermochemistry. III. The Role of Exact Exchange. $J$. Chem. Phys. 98:5648-5652, 1993.

(42) Lee C, Yang W, Parr RG. Development of the Colle-Salvetti Correlation-Energy Formula into a Functional of the Electron Density. Phys. Rev. B 37:785-789, 1988.

(43) Stephens PJ, Devlin FJ, Chabalowski CF, Frisch MJ. Ab Initio Calculation of Vibrational Absorption and Circular Dichroism Spectra Using Density Functional Force Fields. $J$. Phys. Chem. 98:11623-11627, 1994.

(44) Perdew JP. Density-Functional Approximation for the Correlation Energy of the Inhomogeneous Electron Gas. Phys. Rev. B 33:8822-8824, 1986.

(45) Perdew JP, Chevary JA, Vosko SH, Jackson KA, Pederson MR, Singh DJ, Fiolhais C. Atoms, Molecules, Solids, and Surfaces: Applications of the Generalized Gradient Approximation for Exchange and Correlation. Phys. Rev. B 46:6671-6687, 1992.

(46) Perdew JP, Wang Y. Accurate and Simple Analytic Representation of the Electron-Gas Correlation Energy. Phys. Rev. B 45:13244-13249, 1992.

(47) Perdew JP. Electronic Structure of Solids; Ziesche, P., Eschrig, H., Eds.; Akademie Verlag: Berlin, 1991.

(48) Perdew JP, Burke K, Wang Y. Generalized Gradient Approximation for the ExchangeCorrelation Hole of a Many-Electron System. Phys. Rev. B 54:16533-16539, 1996.

(49) Hamprecht FA, Cohen AJ, Tozer DJ, Handy NC. Development and Assessment of New Exchange-Correlation Functionals. J. Chem. Phys. 109:6264-6271, 1998.

(50) Wilson PJ, Bradley TJ, Tozer DJ. Hybrid Exchange-Correlation Functional Determined from Thermochemical Data and Ab Initio Potentials. J. Chem. Phys. 115:9233-9242, 2001.

(51) Grimme S. Semiempirical GGA-Type Density Functional Constructed with a Long-Range Dispersion Correction. J. Comput. Chem. 27:1787-1799, 2006.

(52) Chai J-D, Head-Gordon M. Systematic Optimization of Long-Range Corrected Hybrid Density Functionals. J. Chem. Phys. 128:084106, 2008.

(53) Chai J-D, Head-Gordon M. Long-Range Corrected Hybrid Density Functionals with Damped Atom-Atom Dispersion Corrections. Phys. Chem. Chem. Phys. 10:6615-6620, 2008. 
(54) Schmider HL, Becke AD. Optimized Density Functionals from the Extended G2 Test Set. J. Chem. Phys. 108:9624-9631, 1998.

(55) Becke AD. A New Mixing of Hartree--Fock and Local Density-Functional Theories. J. Chem. Phys. 98:1372-1377, 1993.

(56) Becke AD. Density-Functional Exchange-Energy Approximation with Correct Asymptotic Behavior. Phys. Rev. A 38:3098-3100, 1988.

(57) Perdew JP, Burke K, Ernzerhof M. Generalized Gradient Approximation Made Simple. Phys. Rev. Lett. 77:3865-3868, 1996.

(58) Yanai T, Tew DP, Handy NC. A New Hybrid Exchange-Correlation Functional Using the Coulomb-Attenuating Method (CAM-B3LYP). Chem. Phys. Lett. 393:51-57, 2004.

(59) Boese AD, Handy NC. A New Parametrization of Exchange-Correlation Generalized Gradient Approximation Functionals. J. Chem. Phys. 114:5497-5503, 2001.

(60) Handy NC, Cohen AJ. Left-Right Correlation Energy. Mol. Phys. 99:403-412, 2001.

(61) Adamo C, Barone V. Toward Reliable Density Functional Methods without Adjustable Parameters: The PBE0 Model. J. Chem. Phys. 110:6158-6169, 1999.

(62) Schwabe T, Grimme S. Towards Chemical Accuracy for the Thermodynamics of Large Molecules: New Hybrid Density Functionals Including Non-Local Correlation Effects. Phys. Chem. Chem. Phys. 8:4398-4401, 2006.

(63) Adamo C, Barone V. Exchange Functionals with Improved Long-Range Behavior and Adiabatic Connection Methods without Adjustable Parameters: The mPW and mPW1PW Models. J. Chem. Phys. 108:664-675, 1998.

(64) Xu X, Goddard WA. The X3LYP Extended Density Functional for Accurate Descriptions of Nonbond Interactions, Spin States, and Thermochemical Properties. Proc. Natl. Acad. Sci. U. S. A. 101:2673-2677, 2004.

(65) Boese AD, Martin JML. Development of Density Functionals for Thermochemical Kinetics. J. Chem. Phys. 121:3405-3416, 2004.

(66) Boese AD, Handy NC. New Exchange-Correlation Density Functionals: The Role of the Kinetic-Energy Density. J. Chem. Phys. 116:9559-9569, 2002.

(67) Zhao Y, Truhlar DG. The M06 Suite of Density Functionals for Main Group Thermochemistry, Thermochemical Kinetics, Noncovalent Interactions, Excited States, and Transition Elements: Two New Functionals and Systematic Testing of Four M06Class Functionals and 12 Other Function. Theor. Chem. Acc. 120:215-241, 2008. 
(68) Zhao Y, Truhlar DG. Density Functional for Spectroscopy: No Long-Range SelfInteraction Error, Good Performance for Rydberg and Charge-Transfer States, and Better Performance on Average than B3LYP for Ground States. J. Phys. Chem. A 110:1312613130, 2006.

(69) Zhao Y, Truhlar DG. A New Local Density Functional for Main-Group Thermochemistry, Transition Metal Bonding, Thermochemical Kinetics, and Noncovalent Interactions. J. Chem. Phys. 125:194101, 2006.

(70) Tao J, Perdew JP, Staroverov VN, Scuseria GE. Climbing the Density Functional Ladder: Nonempirical Meta-Generalized Gradient Approximation Designed for Molecules and Solids. Phys. Rev. Lett. 91:146401, 2003.

(71) Staroverov VN, Scuseria GE, Tao J, Perdew JP. Comparative Assessment of a New Nonempirical Density Functional: Molecules and Hydrogen-Bonded Complexes. J. Chem. Phys. 119:12129-12137, 2003.

(72) Krishnan R, Binkley JS, Seeger R, Pople JA. Self-Consistent Molecular Orbital Methods. XX. A Basis Set for Correlated Wave Functions. J. Chem. Phys. 72:650-654, 1980.

(73) McLean AD, Chandler GS. Contracted Gaussian Basis Sets for Molecular Calculations. I. Second Row Atoms, Z=11-18. J. Chem. Phys. 72:5639-5648, 1980.

(74) Wachters AJH. Gaussian Basis Set for Molecular Wavefunctions Containing Third-Row Atoms. J. Chem. Phys. 52:1033-1036, 1970.

(75) Hay PJ. Gaussian Basis Sets for Molecular Calculations. The Representation of 3d Orbitals in Transition-Metal Atoms. J. Chem. Phys. 66:4377-4384, 1977.

(76) Di Valentin C, Costa D. Anatase $\mathrm{TiO}_{2}$ Surface Functionalization by Alkylphosphonic Acid: A DFT+D Study. J. Phys. Chem. C 116:2819-2828, 2012.

(77) Moellmann J, Ehrlich S, Tonner R, Grimme S. A DFT-D Study of Structural and Energetic Properties of $\mathrm{TiO}_{2}$ Modifications. J. Phys. Condens. Matter 24:424206, 2012.

(78) Cramer CJ, Truhlar DG. Density Functional Theory for Transition Metals and Transition Metal Chemistry. Phys. Chem. Chem. Phys. 11:10757-10816, 2009.

(79) Koch W, Holthausen MC. A Chemist's Guide to Density Functional Theory, 2nd ed.; Wiley-VCH: Weinheim, 2001. 